MATEC Web of Conferences 9, 06002 (2013)

DOI: $10.1051 /$ matecconf $/ 20130906002$

(C) Owned by the authors, published by EDP Sciences, 2013

\title{
Gypsum plasterboards enhanced with phase change materials: A fire safety assessment using experimental and computational techniques
}

\author{
Dionysios I. Kolaitisa ${ }^{a}$ Eleni K. Asimakopoulou and Maria A. Founti \\ Laboratory of Heterogeneous Mixtures and Combustion Systems, School of Mechanical \\ Engineering, National Technical University of Athens, 9 Heroon Polytechneiou St., \\ Polytechneioupoli Zografou, Athens 15780, Greece
}

\begin{abstract}
Phase Change Materials (PCM) can be used for thermal energy storage, aiming to enhance building energy efficiency. Recently, gypsum plasterboards with incorporated paraffin-based PCM blends have become commercially available. In the high temperature environment developed during a fire, the paraffins, which exhibit relatively low boiling points, may evaporate and, escaping through the gypsum plasterboard's porous structure, emerge to the fire region, where they may ignite, thus adversely affecting the fire resistance characteristics of the building. Aiming to assess the fire safety behaviour of such building materials, an extensive experimental and computational analysis is performed. The fire behaviour and the main thermo-physical physical properties of PCM-enhanced gypsum plasterboards are investigated, using a variety of standard tests and devices (Scanning Electron Microscopy, Thermo Gravimetric Analysis, Cone Calorimeter). The obtained results are used to develop a dedicated numerical model, which is implemented in a CFD code. CFD simulations are validated using measurements obtained in a cone calorimeter. In addition, the CFD code is used to simulate an ISO 9705 room exposed to fire conditions, demonstrating that PCM addition may indeed adversely affect the fire safety of a gypsum plasterboard clad building.
\end{abstract}

\section{INTRODUCTION}

Uncontrollable fires in buildings represent a significant part of fire-related fatalities. Investigation of commonly used, as well as innovative, building materials' fire behaviour is of primary interest since the developed thermal environment and the production of toxic gases are associated with a large range of hazards to human life and properties. In building fires, the confined space controls the ventilation conditions and fuel load affect the developing thermal field, thus influencing the thermal exposure of structural elements [1]. Experimental and numerical methods can be utilized for the understanding of the dynamics of a fire incident, the estimation of structural fire resistance and the quantification of its overall impact on buildings and people; both approaches are equally valuable to analyse the occurring physical and chemical phenomena.

\subsection{Fire behaviour of gypsum plasterboards}

Gypsum plasterboards (GP) are widely used in the building industry for a variety of applications as an aesthetically pleasing, easily applied and mechanically enduring facing material for walls and ceilings. In the context of building fire safety, gypsum plasterboards are capable of decelerating the penetration of fire through walls and floors, due to the endothermic gypsum dehydration process occurring in high

ae-mail: dkol@central.ntua.gr

This is an Open Access article distributed under the terms of the Creative Commons Attribution License 2.0, which permits unrestricted use, distribution, and reproduction in any medium, provided the original work is properly cited. 


\section{MATEC Web of Conferences}

temperatures. When a GP is subjected to a high temperature environment, water molecules bound in its crystal lattice are released and transferred through the board, absorbing energy and thus reducing the mean wall temperature. This process is known to improve the fire resistance of the wall assembly, thus enhancing the safety margins of the building, by allowing longer evacuation times [2].

A typical GP consists mainly of calcium sulphate di-hydrate $\left(\mathrm{CaSO}_{4} \cdot 2 \mathrm{H}_{2} \mathrm{O}\right)$, which contains $21 \%$ (by weight) chemically bound water. When gypsum is heated above $90^{\circ} \mathrm{C}$, the chemically bound water dissociates from the crystal lattice and evaporates. This process, known as gypsum "dehydration", occurs in the temperature region between $90^{\circ} \mathrm{C}$ and $250^{\circ} \mathrm{C}$, depending on the heating rate; dehydration reactions are strongly endothermic, thus requiring large amounts of heat [3]. The dissociation of the chemically bound water takes place in two stages. In the first stage (Eq. (1)), the calcium sulphate dihydrate loses $75 \%$ of its water, thus forming calcium sulphate hemi-hydrate $\left(\mathrm{CaSO}_{4} \cdot \frac{1}{2} \mathrm{H}_{2} \mathrm{O}\right)$. Further heating results in the onset of a second reaction (Eq. (2)), where the calcium sulphate hemi-hydrate loses the remaining water to form calcium sulphate anhydrite $\left(\mathrm{CaSO}_{4}\right)$. Both reactions are highly endothermic.

$$
\begin{gathered}
\mathrm{CaSO}_{4} \cdot 2 \mathrm{H}_{2} \mathrm{O}_{(\mathrm{s})}=>\mathrm{CaSO}_{4} \cdot 1 / 2 \mathrm{H}_{2} \mathrm{O}_{(\mathrm{s})}+3 / 2 \mathrm{H}_{2} \mathrm{O}_{(\mathrm{g})} \\
\mathrm{CaSO}_{4} \cdot 1 / 2 \mathrm{H}_{2} \mathrm{O}_{(\mathrm{s})}=>\mathrm{CaSO}_{4(\mathrm{~s})}+1 / 2 \mathrm{H}_{2} \mathrm{O}_{(\mathrm{g})} .
\end{gathered}
$$

Both gypsum dehydration and water vapour diffusion have a strong impact on the heat transfer characteristics of GP exposed to fire conditions. Accurate modelling of these phenomena requires the detailed solution of the respective heat and mass transfer equations across the width of the GP [3]. In the context of a CFD analysis, the computational cost of such detailed simulations is currently prohibitive; therefore, various alternative methodologies have been developed [4].

\subsection{Use of phase change materials in buildings}

Phase Change Materials (PCM) are used in a wide range of applications; they can be incorporated in building materials, aiming to increase the thermal mass storage capacity of a building [5, 6]. This innovative technique takes advantage of the latent heat of the PCM during the solid-to-liquid phase change to reduce the indoor temperature fluctuations and the heat losses/gains between the building and the environment. PCM can be incorporated in concrete, gypsum plasterboards, plaster and other building materials. Traditional methods for incorporating PCM, such as direct incorporation, immersion and macro-encapsulation, have fallen into disuse due to leakage problems, incompatibility, tendency of solidification at the edges, poor thermal conductivity and complicated integration to the building materials [7]. PCM micro-encapsulation is increasingly used as an easier and more economic way of incorporation into construction materials [8]. In PCM micro-encapsulation, the PCM is enclosed in thin sealed polymer spherical capsules, ranging in size from $1 \mu \mathrm{m}$ to $300 \mu \mathrm{m}$, which can maintain their shape and prevent leakage during the phase change process [9].

In commercially available products, the solid-liquid phase change occurs in the typical indoor temperature ranges $\left(20-26^{\circ} \mathrm{C}\right)$, and it is favourable for building energy consumption purposes. However, in a fire event, building materials may be exposed to substantially higher temperatures, that may reach $800^{\circ} \mathrm{C}$; in this case, there is a high possibility for leakage, which would allow PCM vapours to be directly exposed to the fire environment $[5,10]$. In such intense heating conditions, paraffinbased PCM, exhibiting boiling points below $350{ }^{\circ} \mathrm{C}$, evaporate. If the PCM encapsulation shell is broken, due to the high temperature environment, the produced paraffin vapours will be released to the porous structure of the gypsum plasterboard and, through mass diffusion processes, will emerge to the main combustion region. In this case, paraffin vapours are expected to ignite, adversely affecting the building's fire resistance characteristics [11]. In this context, the fire behaviour of PCM enriched GP wall assemblies and the associated impact on building fire safety is investigated in the current study, using both experimental and numerical techniques. 

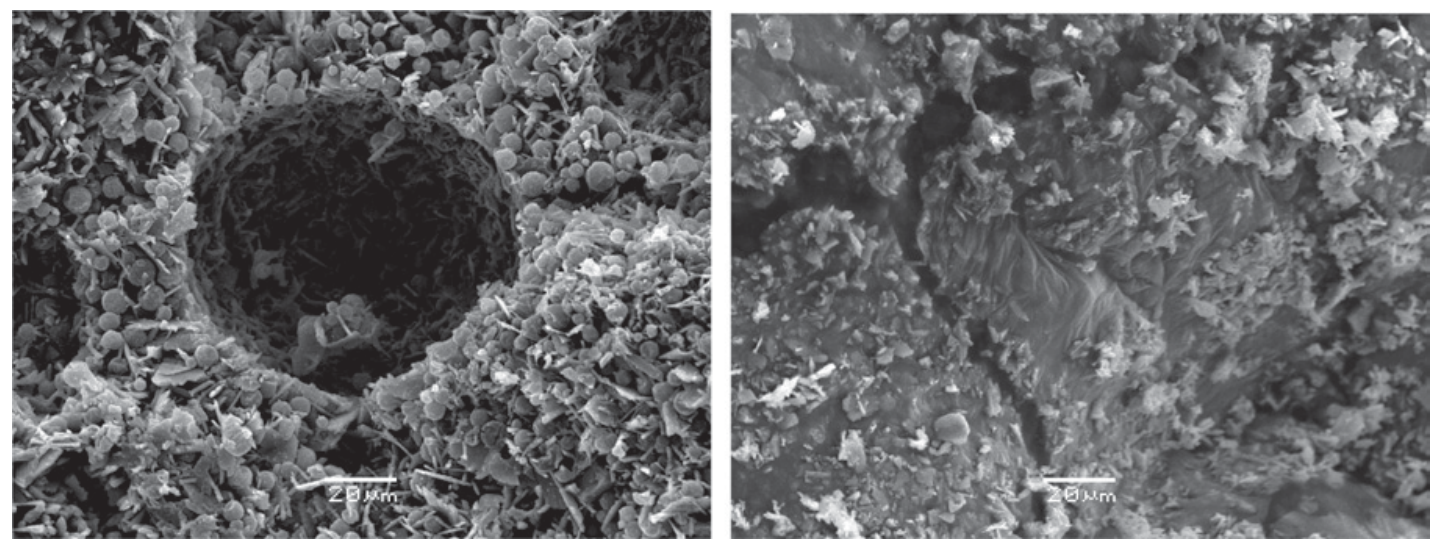

Figure 1. SEM photographs of GP+PCM samples before (left) and after (right) heat flux exposure.

\section{EXPERIMENTAL INVESTIGATION}

In order to characterize the fire behaviour of GP enhanced with micro-encapsulated PCM, a detailed knowledge of the temperature-dependent thermo-physical properties, associated with the behaviour of the respective building materials in high temperatures and intense heating rates, is required. In this context, a detailed experimental investigation has been performed using a variety of well established test methods. Aiming to assess the impact of PCM addition in the fire behaviour of GP, all measurements have been performed in samples of both commercially available gypsum plasterboards (GP) and PCMenriched gypsum plasterboards (GP+PCM).

\subsection{Scanning Electron Microscopy}

A Jeol JSM-5600 Scanning Electron Microscope (SEM), equipped with an X-ray EDS (Energy Dispersive X-ray Spectroscopy) micro-probe has been used to investigate the micro-structure of $\mathrm{GP}+\mathrm{PCM}$ samples before and after exposure to a $75 \mathrm{~kW} / \mathrm{m}^{2}$ heat flux in a cone calorimeter. The goldcovered samples have been observed at $20 \mathrm{keV}$ for $60 \mathrm{~s}$. The SEM photograph of the PCM-enriched GP before being exposed to the intense heat flux reveals the porous structure of the GP (Fig. 1, left). The micro-encapsulated PCM spheres are also clearly depicted; the average capsule diameter in the examined sample is of the order of $5 \mu \mathrm{m}$. Significant changes are observed in the microstructure of the GP+PCM samples after exposure to a $75 \mathrm{~kW} / \mathrm{m}^{2}$ heat flux (Fig. 1, right); thermally-induced cracks are evident, while the remaining crystals of the calcium sulphate anhydrite are surrounded by a homogeneous melted mixture of calcium, sulfur and silicon. The spherical polymer PCM-enclosing capsules are almost completely destroyed, thus suggesting that the produced PCM vapours are being released to the ambient.

\subsection{Thermo-Gravimetric Analysis}

Aiming to investigate the thermal behaviour of commercial GP enhanced with micro-encapsulated paraffin based PCM, a series of Differential Scanning Calorimetry (DSC) and Thermo-Gravimetric Analysis (TGA) tests has been performed, using inert gas (He) conditions in a SETARAM TGA device. Comparative TGA measurements in both "plain" (GP) and "PCM-enhanced" (GP+PCM) gypsum plasterboards have been made, using a relative high heating rate $\left(50{ }^{\circ} \mathrm{C} / \mathrm{min}\right)$, corresponding to an "intense" fire environment. The samples, weighing $79.5 \mathrm{mg}$ and $69.5 \mathrm{mg}$ respectively, were placed in aluminum crucibles with a pinhole lid (negligible $\mathrm{p}_{\mathrm{H} 2 \mathrm{O}}$ atmosphere) and were subjected to a constant 
MATEC Web of Conferences
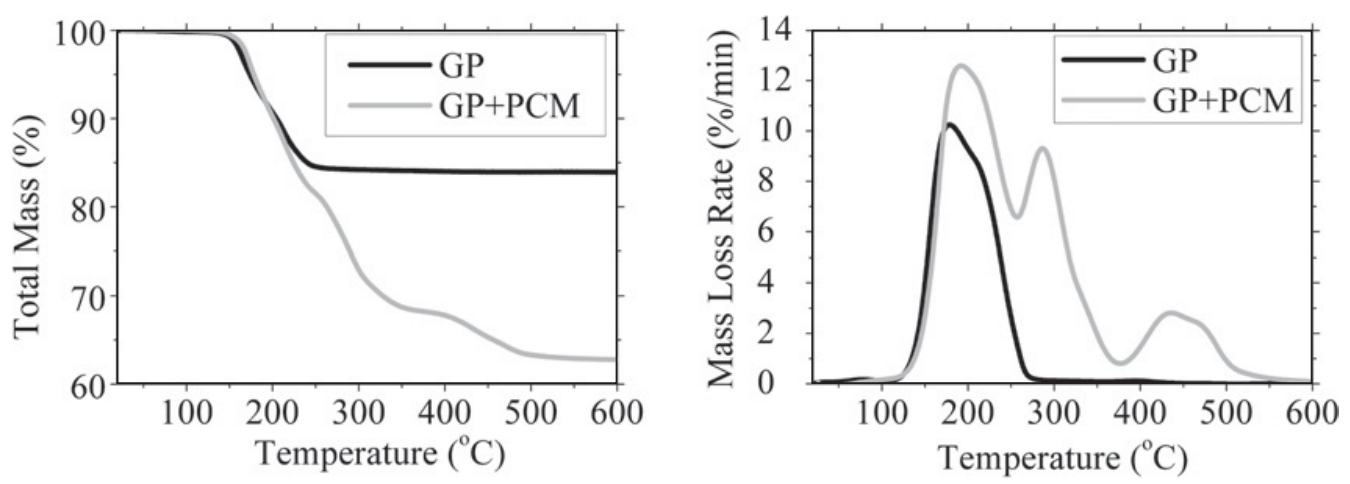

Figure 2. Mass loss (left) and mass loss rate (right) of GP and GP+PCM samples $\left(50^{\circ} \mathrm{C} / \mathrm{min}\right)$.

heating rate $\left(50^{\circ} \mathrm{C} / \mathrm{min}\right)$ from ambient temperature $\left(20^{\circ} \mathrm{C}\right)$ up to $600^{\circ} \mathrm{C}$. The TGA device used performed simultaneously a DSC analysis that allowed the quantification of enthalpy changes during sample decomposition.

Initially, both GP and GP+PCM samples exhibit similar mass loss behaviour (Fig. 2), which corresponds to the onset of gypsum dehydration reactions (Eqs. (1) and (2)). However, at temperatures higher than $250^{\circ} \mathrm{C}$, the behaviour of the GP+PCM sample is differentiated, suggesting the emergence of two additional significant thermal events. The first event, observed at approximately $330^{\circ} \mathrm{C}$, is attributed to the evaporation of the PCM blend, whereas the second event, occurring at $450{ }^{\circ} \mathrm{C}$, is associated with the destruction of the micro-capsules' polymer shell [12,13]. TGA results (Fig. 2) suggest that approximately $18 \%$ of the GP+PCM sample mass is lost during the gypsum dehydration process, $12 \%$ is lost due to paraffin evaporation and 5\% due to the polymer shell decomposition. Hence the initial concentration of PCM in the GP+PCM sample is assumed to be $12 \%$.

Commercially available paraffin-based PCM contain a large variety of paraffin species, thus allowing better control of the overall thermal behaviour. The exact composition of the PCM paraffin blend used in the examined GP+PCM samples was unavailable. In order to estimate the chemical composition of the paraffin PCM blend, an additional series of TGA measurements has been performed, using significantly lower heating rates $\left(0.5-5^{\circ} \mathrm{C} / \mathrm{min}\right)$. Focusing on the solid-to-liquid phase change process, it has been found that the melting point of the PCM blend $\left(18-19^{\circ} \mathrm{C}\right)$ correlates favourably to that of hexadecane $\left(\mathrm{C}_{16} \mathrm{H}_{34}\right.$, exhibiting a $18^{\circ} \mathrm{C}$ melting point $)$.

\subsection{Cone Calorimeter}

An ISO 5660-1 Cone Calorimeter (CC) has been used to investigate the fire behaviour of both GP and GP+PCM specimens. Tests have been performed at two heat flux levels, $50 \mathrm{~kW} / \mathrm{m}^{2}$, corresponding to the stage of fire development and $75 \mathrm{~kW} / \mathrm{m}^{2}$, corresponding to a fully developed fire [14]. The tested specimens were horizontally mounted; the non-exposed surfaces were wrapped with aluminum foil and insulated. The distance from the specimen surface to the cone heater was equal to $25 \mathrm{~mm}$. The main specimen properties for the 4 tests performed are given in Table 1. All specimens were pre-conditioned carefully for more than a week in a controlled environment of $23^{\circ} \mathrm{C}$ and $50 \%$ relative humidity. In each test, one type $\mathrm{K}$ thermocouple was placed at the bottom face, in order to monitor the temperature change at the unexposed side.

In the standard CC test, the specimen ignitability is determined by observing the time for sustained ignition. Both GP and GP+PCM specimens were characterized as non-charring materials. After the test, GP specimens showed minimal external damage (Fig. 3); the cover paper was burnt and no significant 
$1^{\text {st }}$ International Seminar for Fire Safety of Facades, Paris (France), 2013

Table 1. Main physical parameters for the performed Cone Calorimeter tests.

\begin{tabular}{lllllll}
\hline Test & Material & $\begin{array}{l}\text { Incident } \\
\text { Heat Flux } \\
\left(\mathrm{kW} / \mathrm{m}^{2}\right)\end{array}$ & $\begin{array}{l}\text { Specimen } \\
\text { Thickness } \\
(\mathrm{mm})\end{array}$ & $\begin{array}{l}\text { Specimen } \\
\text { Dimensions } \\
(\mathrm{mm} \times \mathrm{mm})\end{array}$ & $\begin{array}{l}\text { mass } \\
(\mathrm{g})\end{array}$ & $\begin{array}{l}\text { Exposed } \\
\text { surface } \\
\left(\mathrm{cm}^{2}\right)\end{array}$ \\
\hline GP-50 & GP & 50 & 9.35 & $101.2 \times 102$ & 88.6 & 88.4 \\
GP-75 & GP & 75 & 12.30 & $100.7 \times 101$ & 90.0 & 88.4 \\
GP+PCM-50 & GP+PCM & 50 & 15.18 & $99.94 \times 98$ & 114.9 & 88.4 \\
GP+PCM-75 & GP+PCM & 75 & 15.20 & $101.9 \times 99.5$ & 118.6 & 88.4 \\
\hline
\end{tabular}
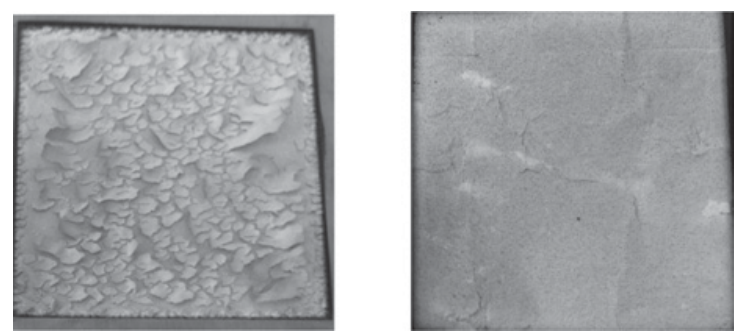

Figure 3. Surface photographs of the GP (left) and GP+PCM (right) specimens $\left(75 \mathrm{~kW} / \mathrm{m}^{2}\right)$.
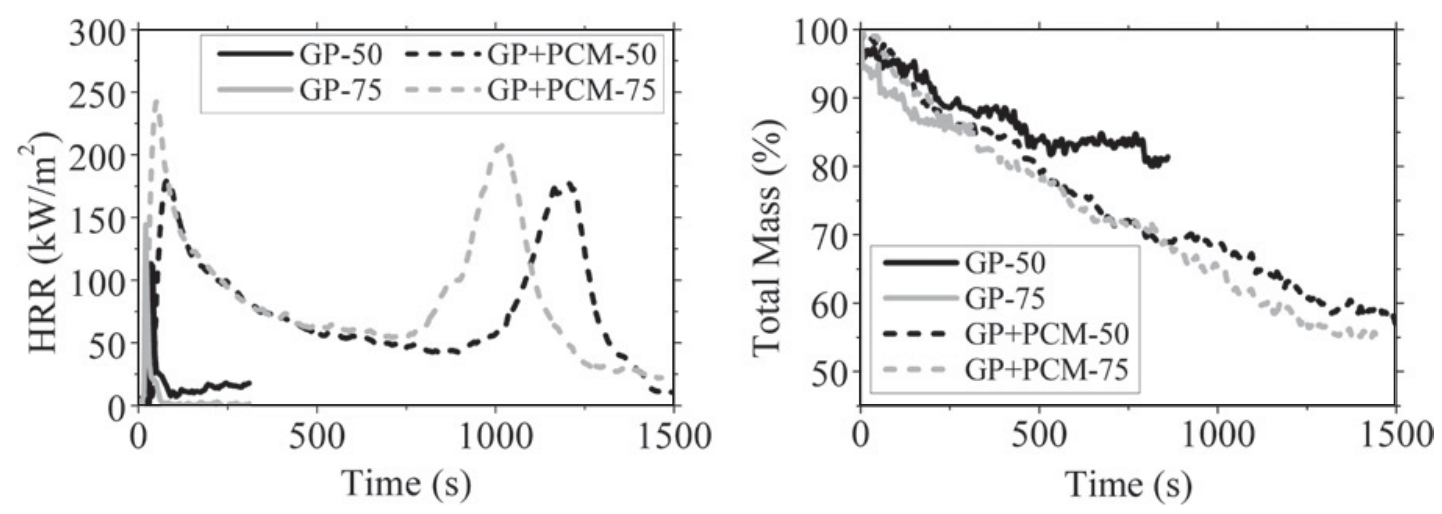

Figure 4. Heat release rate (left) and total mass (right) of GP and GP+PCM samples.

cracking was observed. On the contrary, the GP+PCM specimens showed extensive external cracking and increased brittleness.

The temporal evolution of the measured Heat Release Rate (HRR) is shown, for all 4 considered test cases, in Figure 4 (left). An initial sharp HRR peak can be observed in all cases; this is attributed to the burning of the cover paper [15]. As expected, due to PCM evaporation and subsequent PCM vapour combustion, GP+PCM specimens exhibit significantly higher HRR values compared to the GP specimens. Two major HRR peaks are observed in both GP+PCM cases; the first is attributed to the prompt evaporation of the near surface PCM material, while the second, which is significantly delayed, corresponds to the delayed release of the evaporated PCM that follows the thermal failure of the polymer capsule shell. As expected, increasing the incident heat flux level results in higher peak HRR values and shorter ignition times. In addition, mass loss rate measurements (Fig. 4, right) suggest that the GP+PCM specimens result in higher total mass loss and mass loss rates as well. 


\section{MATEC Web of Conferences}

\section{NUMERICAL SIMULATIONS}

The constantly increasing worldwide trend of implementing "performance-based" fire safety codes requires the utilization of dedicated computational tools. The most advanced modelling tools available today, which can be used in a wide field of applications related to building fire safety, are Computational Fluid Dynamics (CFD) codes. In this context, aiming to accurately describe the fire behaviour of GP+PCM wall assemblies, a dedicated numerical model, based on solid reaction kinetics is developed. The numerical model is implemented in a CFD code and is validated using the obtained CC measurements; in addition, a room-façade fire arrangement is simulated aiming to demonstrate the potential adverse effects of PCM on the fire safety of GP clad buildings.

\subsection{Description of the CFD Code}

The Fire Dynamic Simulator (FDS, Version 5.5.3) is used to perform the CFD simulations. The FDS code, developed by NIST [16], is a CFD tool capable of studying fundamental fire dynamics and combustion, aimed at solving practical fire problems in fire protection engineering. A form of the NavierStokes equations, appropriate for low-speed, thermally driven flows, emphasizing on smoke production and heat transfer from fires, are numerically solved, using a three-dimensional, Cartesian grid. The core algorithm is a semi-implicit (explicit in velocity and implicit in pressure) predictor-corrector scheme that is second order accurate in space and time, by using central differences. The time step is dynamically adjusted in order to satisfy the CFL criterion. Turbulence is modelled using the Large Eddy Simulation (LES) approach for length scales smaller than those that are explicitly resolved on the numerical grid. The subgrid-scale turbulence is simulated using the Smagorinsky model, utilizing a Smagorinsky constant value of 0.2 in order to maintain numerical stability. Thermal radiation is simulated using the finite volume methodology on the same grid as the flow solver. Conjugate heat transfer in solid bodies immersed in the computational domain are simulated by solving an one-dimensional heat transfer equation in the direction normal to the solid surface; a dedicated non-uniform mesh, independent of the CFD computational mesh, is used for the respective simulations. CFD predictions of convective and radiative heat flux on the surfaces of the solid bodies are used as boundary conditions for the solid heat transfer simulations. Multi-layered wall assemblies can be simulated by utilizing detailed thermophysical properties (e.g. density, thermal conductivity, specific heat) for each material. Solid reactions (e.g. pyrolysis) can be modelled by using appropriate chemical kinetics models. Predictions of the FDS code have been extensively validated [17].

\subsection{Development of a dedicated numerical model}

A dedicated numerical model is developed to simulate the fire behaviour of GP+PCM wall assemblies. The developed model is focused on describing the PCM evaporation process, which results in combustible PCM vapours emerging in the fire compartment. Due to lack of information regarding the physical and chemical properties of the polymer capsule shell, the effects of the capsule disintegration process are neglected; as a result, when the paraffin-based PCM is evaporated, it is assumed to be immediately released through the GP porous structure. This assumption corresponds to the "worst case scenario", which is, however, supported by the lack of intact polymer capsule shells in the SEM photographs of GP+PCM samples after being exposed to intense heat flux (cf. Fig. 1, right).

Aiming to limit the complexity of the developed model, a single-species PCM is considered; in order to select the proper "surrogate" species, a series of low heating rate TGA tests has been performed (cf. Sect. 2.2). Based on melting point measurements, hexadecane $\left(\mathrm{C}_{16} \mathrm{H}_{34}\right)$ has been selected as a singlespecies surrogate of the actual paraffin PCM blend of the investigated GP+PCM sample. As a result, the main thermo-physical properties used for modelling purposes, such as latent heat of evaporation $(209.97 \mathrm{~kJ} / \mathrm{kg})$ and lower heating value $(43950 \mathrm{~kJ} / \mathrm{kg})$, are these of hexadecane [18]. The hexadecane 
$1^{\text {st }}$ International Seminar for Fire Safety of Facades, Paris (France), 2013

Table 2. Model parameters for the solid reaction kinetics model.

\begin{tabular}{lllll}
\hline Model Parameter & Units & Equation 1 & Equation 2 & Equation 3 \\
\hline Reactant & $(-)$ & $\mathrm{CaSO}_{4} \cdot 2 \mathrm{H}_{2} \mathrm{O}$ & $\mathrm{CaSO}_{4} \cdot{ }_{1 / 2} \mathrm{H}_{2} \mathrm{O}$ & $\mathrm{C}_{16} \mathrm{H}_{34}$ \\
Product (solid) & $(-)$ & $\mathrm{CaSO}_{4} \cdot 1 / 2 \mathrm{H}_{2} \mathrm{O}$ & $\mathrm{CaSO}_{4}$ & - \\
Product (gaseous) & $(-)$ & $\mathrm{H}_{2} \mathrm{O}$ & $\mathrm{H}_{2} \mathrm{O}$ & $\mathrm{C}_{16} \mathrm{H}_{34}$ \\
$v_{\text {res }}$ & $(\mathrm{kg} / \mathrm{kg}$ reactant) & $87.85 \%$ & $95.20 \%$ & $0 \%$ \\
$v_{\mathrm{H}_{2} \mathrm{O}}$ & $(\mathrm{kg} / \mathrm{kg}$ reactant) & $12.15 \%$ & $4.80 \%$ & $0 \%$ \\
$v_{\text {gas }}$ & $(\mathrm{kg} / \mathrm{kg}$ reactant) & $0 \%$ & $0 \%$ & $100 \%$ \\
$A$ & $\left(\mathrm{~s}^{-1}\right)$ & $1.16407 \times 10^{17}$ & $2.95661 \times 10^{7}$ & $2.92152 \times 10^{10}$ \\
$E$ & $(\mathrm{~kJ} / \mathrm{kmol})$ & 148636.15 & 78628.42 & 138170.94 \\
$n$ & $(-)$ & 1 & 1 & 1 \\
Endothermic Heat & $(\mathrm{kJ} / \mathrm{kg})$ & 329.79 & 109.93 & 209.97 \\
\hline
\end{tabular}

evaporation process is described using a first-order chemical reaction approximation (Eq. (3)).

$$
\mathrm{C}_{16} \mathrm{H}_{34(\mathrm{l})}=>\mathrm{C}_{16} \mathrm{H}_{34(\mathrm{~g})} \text {. }
$$

Simulation of solid phase reactions is commonly performed utilizing the Arrhenius equation formulation. The general form of the Arrhenius equation, used to determine the reaction rate $\left(r_{j}\right)$ of the $j$-th chemical reaction that involves the i-th solid species as a reactant, is shown in Eq. (1). The required kinetic parameters are the pre-exponential factor $\left(A_{j}\right)$, the activation energy $\left(E_{j}\right)$ and the reaction order $\left(n_{j}\right)$. Selection of the proper kinetic parameters for solid reactions is a very challenging task; values derived from small and large-scale experiments may exhibit differences of several orders of magnitude. In the FDS code, each solid component undergoing a chemical reaction may simultaneously yield userdefined quantities of solid residue $\left(v_{\text {res }}\right)$, water vapour $\left(v_{\mathrm{H}_{2} \mathrm{O}}\right)$ and combustible gaseous fuel $\left(v_{\text {gas }}\right)$. In the case of the GP+PCM model, water vapour is released due to the gypsum dehydration reactions (Eqs. (1) and (2)) and combustible hexadecane vapours due to PCM evaporation (Eq. (3)).

$$
r_{j}=A_{j} Y_{s, i}^{n_{j}} \exp \left(-\frac{E_{j}}{R T}\right)
$$

The developed GP+PCM model is essentially an extension of a solid reaction kinetics model developed by the authors [4]. The original GP model [4] uses the Arrhenius equation formulation to simulate the two gypsum dehydration reactions (Eqs. (1) and (2)); the relevant kinetic parameters, obtained by DSC measurements, are shown in Table 2. The GP model has been implemented in the FDS code and has been validated against available temperature measurements from a GP assembly tested in a small-scale fire resistance furnace [4]. The proposed GP+PCM model comprises the original gypsum dehydration model plus the additional PCM evaporation "reaction" (Eq. (3)). The kinetic parameters for PCM evaporation are determined by the TGA measurements, using the methodology proposed by Lyon [19]; the obtained values are given in Table 2. The developed GP+PCM model is implemented in the FDS code. If the predicted temperature of the GP+PCM material exceeds the boiling point of PCM, hexadecane vapours are released, through the GP porous structure, to the fire compartment. The produced vapours can be subsequently ignited and burnt, thus increasing the total fire load of the compartment.

The developed model is appropriate for simulation of both GP and GP+PCM wall assemblies. When a plain GP is considered, only Eqs. (1) and (2) are "activated"; the initial material composition is assumed to be $100 \% \mathrm{CaSO}_{4} \cdot 2 \mathrm{H}_{2} \mathrm{O}$. On the other hand, when a $\mathrm{GP}+\mathrm{PCM}$ material is simulated, Eqs. (1), (2) and (3) are taken into account; in this case, the initial composition is assumed to be $78 \%$ $\mathrm{CaSO}_{4} \cdot 2 \mathrm{H}_{2} \mathrm{O}$ and $12 \%$ hexadecane $(\mathrm{PCM})$. 

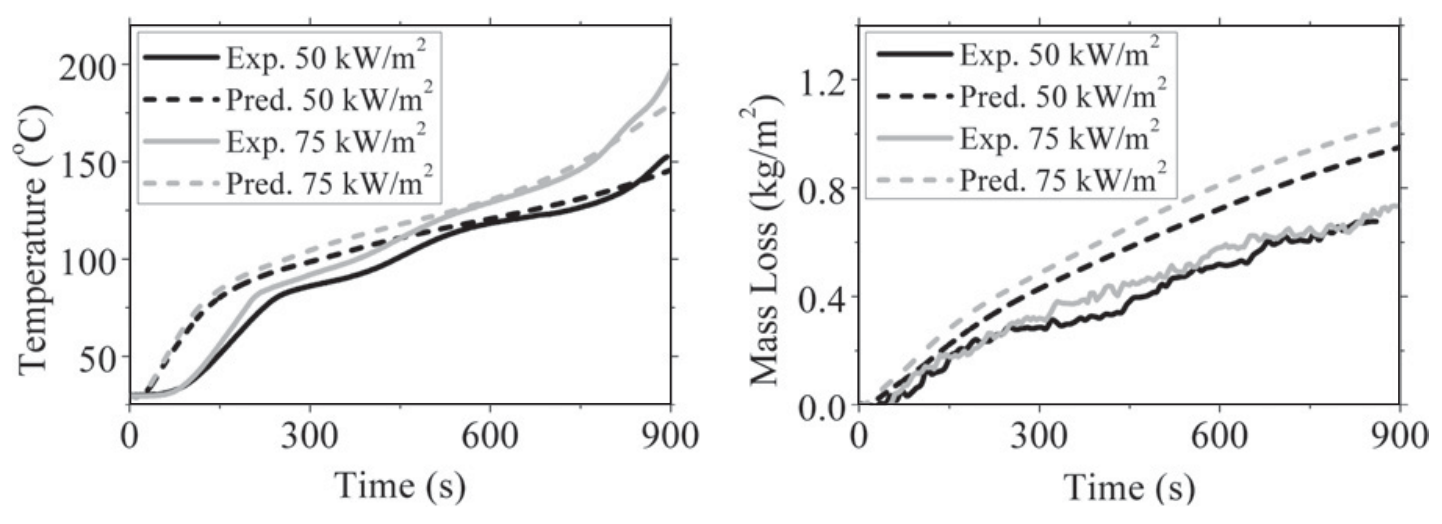

Figure 5. Temporal evolution of temperature (left) and mass loss (right) of GP+PCM samples.

\subsection{Validation study}

The developed GP+PCM model is validated by performing CFD simulations of the CC tests presented in Section 2.3. A simple geometrical arrangement is used, consisting of the $100 \times 100 \times 10 \mathrm{~mm}$ specimen and a "virtual" heat flux source attached on the upper surface of the specimen. A computational time of $900 \mathrm{~s}$ is used, following the experimental procedure; the minimum numerical time-step, which is dynamically adjusted by the FDS code, is $10 \mathrm{~ms}$. In Figure 5, predictions of the temporal evolution of the unexposed surface temperature and the mass loss rate are compared to available measurements for both CC tests (at $50 \mathrm{~kW} / \mathrm{m}^{2}$ and $75 \mathrm{~kW} / \mathrm{m}^{2}$ ). Despite the "crude" geometrical approximation and the modelling assumptions, good quantitative agreement is achieved for the temperature and qualitative for the mass loss. Inaccuracies in the predictions of mass loss may be associated with the modelling assumptions, especially regarding the initial composition of the GP+PCM specimen and the polymer capsule disintegration process. This remark corroborates the ability of the developed model to simulate the main physico-chemical phenomena associated with the fire behaviour of GP+PCM building materials, i.e. gypsum dehydration and PCM evaporation, in sufficient detail.

\subsection{Application in a large scale fire compartment-Façade arrangement}

In order to investigate the effects of PCM addition to the fire safety characteristics of a GP clad building, a large-scale fire compartment CFD simulation is performed. In this case, the standard "Room Corner Test" (ISO 9705) geometry is used, in conjunction with a $5 \mathrm{~m}$ high façade. The fire compartment dimensions are $2.4 \mathrm{~m} \times 3.6 \mathrm{~m} \times 2.4 \mathrm{~m}$; a $0.8 \mathrm{~m} \times 2.0 \mathrm{~m}$ open door is located on a rectangular side wall. The fire source is assumed to be a rectangular $(1.0 \mathrm{~m} \times 1.0 \mathrm{~m})$ burner, located at the geometrical centre of the room; the burner is fed with n-heptane, exhibiting a constant $2070 \mathrm{~kW}$ heat release rate. In the two test cases studied, all simulation parameters are identical, except from the material used to construct the room walls. In the first test case (GP), which serves as a basis for comparison, $25 \mathrm{~mm}(2 \times$ $12.5 \mathrm{~mm}$ ) "conventional" gypsum plasterboards are used to clad the room walls. In the second test case (GP+PCM), paraffin-based PCM are assumed to be incorporated to the $25 \mathrm{~mm}$ gypsum plasterboards. In both cases, the façade is considered to be clad in "plain" GP. Detailed temperature-dependent physical properties of GP are used to describe their thermal behaviour [4].

Predictions of the predicted flame shape and the façade surface temperatures, $10 \mathrm{~min}$ after fire initiation, are depicted in Figure 6. The flame shape and location in the GP case is similar to a typical pool fire burning in the open environment; the recirculation zone created by air entrainment near the opening leads to a slight deformation of the flame shape, which results in a "drift" towards the "rear" side of the enclosure. It is evident that paraffin vapour evaporation in the GP+PCM case results in a 

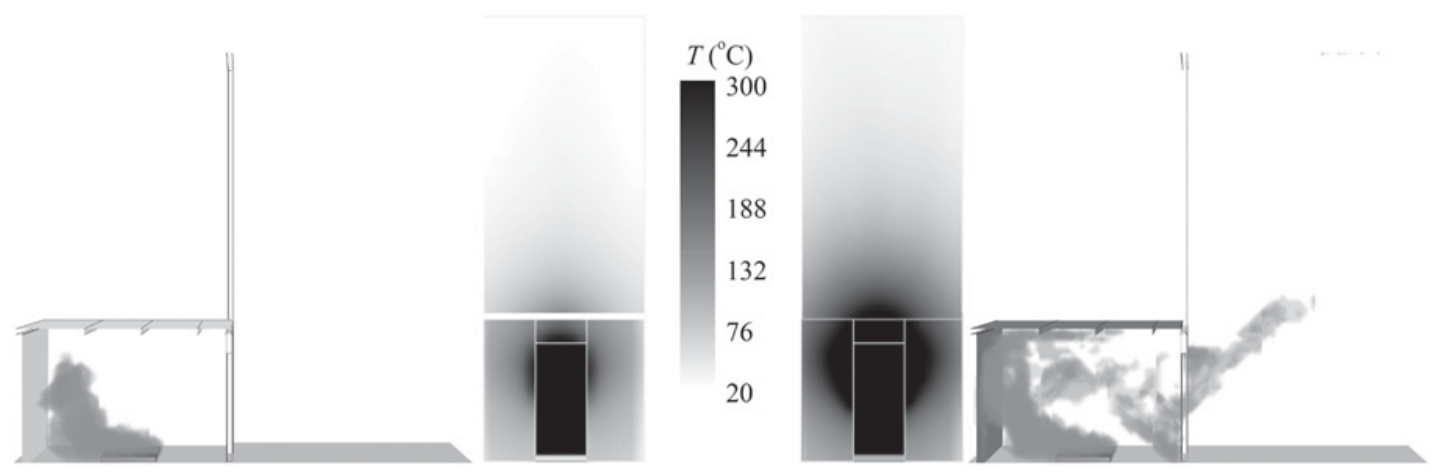

Figure 6. CFD predictions of flame location and facade exposed surface temperatures, $10 \mathrm{~min}$ after fire initiation, for test cases GP (left) and GP+PCM (right).
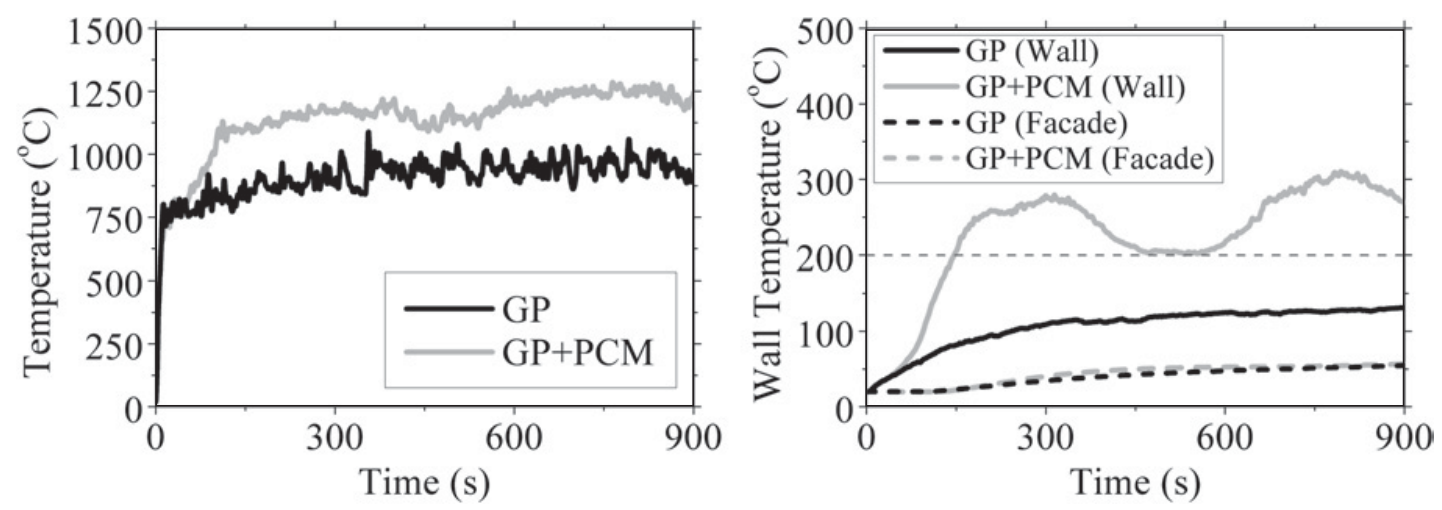

Figure 7. CFD predictions of the temporal evolution of the compartment gas temperature (left) and unexposed surface temperatures at the compartment front wall and the façade (right).

significant enhancement of the fire intensity and extension of the flame compared to the GP case. As expected, temperature predictions at the exposed façade surface are noticeably higher in the case of PCM-enriched GP; it is evident that the produced amount of "combustible" paraffin vapours enhances the fire power, thus resulting in higher wall temperatures.

Predictions of the temporal evolution of the gas temperature inside the compartment, near the back wall at a height of $2 \mathrm{~m}$ are depicted in Figure 6 (left) for both test cases. The observed oscillating behaviour is mainly attributed to the "puffing" phenomena commonly observed in pool fires. It is evident that the predicted gas temperatures are higher in the GP+PCM case, due to the intensification of the fire created by the combustion of the released PCM vapours.

CFD tools allow the estimation of the fire resistance characteristics of wall assemblies. In this context, the performed simulations are used to investigate the fire resistance of the utilized GP wall assemblies. GP exposed to fire are considered to exhibit mechanical failure when cracks or openings are observed through the wall [20]; however, since cracking phenomena cannot be accurately simulated in the FDS code, alternative failure criteria are used in this study. According to the Eurocode standards [21], fire safety regulations regarding the "integrity" of a compartment wall assembly specify that the maximum temperature rise at the unexposed side (ambient facing side) should not exceed $180^{\circ} \mathrm{C}$. In the current simulations, the ambient temperature was considered to be $20^{\circ} \mathrm{C}$; therefore, the aforementioned "failure" criterion for a GP wall assembly corresponds to a temperature of $200{ }^{\circ} \mathrm{C}$ on its unexposed side. 


\section{MATEC Web of Conferences}

Predictions of the temporal evolution of the unexposed side temperatures for the compartment front wall and the façade are depicted in Figure 7 (right); the illustrated numerical results are obtained at a height of $1.2 \mathrm{~m}$ and $2.6 \mathrm{~m}$, respectively. It is evident that the façade does not exceed the Eurocode fire resistance "failure" criterion (temperature at the unexposed side higher than $200{ }^{\circ} \mathrm{C}$ ) in both cases. However, in the PCM-enriched GP case (GP+PCM), predicted temperatures at the unexposed side of the compartment front wall, which lies close to the opening, exceed the critical failure limit of $200{ }^{\circ} \mathrm{C}$ approximately $150 \mathrm{~s}$ after fire initiation. In the GP case, no "failure" event is observed at the front wall, thus demonstrating the potential adverse effects of PCM enrichment on the fire safety characteristics of GP clad compartments.

\section{CONCLUSIONS}

Thermal energy storage using PCM enhanced building materials provides significant advantages in terms of building energy consumption. In this context, there are already commercially available GP which incorporate micro-encapsulated paraffin-based PCM; these innovative building materials exhibit various desirable characteristics, such as high heat of fusion, variable phase change temperature, no phase segregation and low cost, but they may compromise the fire resistance characteristics of the building. Aiming to investigate the effect of PCM addition in the fire safety characteristics of GP clad buildings, an extensive experimental and numerical study has been performed. The thermo-physical properties of PCM-enhanced GP have been measured using a variety of standard tests (SEM, TGA, DSC and CC). In addition, a dedicated numerical model has been developed, capable of describing in sufficient detail the gypsum dehydration and PCM evaporation phenomena. The model has been implemented in a CFD code and validated against CC measurements. Also, using a large-scale fire compartment-façade test case, the potential adverse impact of combusting PCM vapours on the fire safety of GP clad buildings has been demonstrated. Further investigation is planned to be carried out on the effects of PCM incorporation methods, flame retardant addition in PCM blends and application of non-flammable capsule surface coatings.

This study has been financially supported by the "Fire-Facts" project in the frame of the ARISTEIA action (operational programme "Education and Lifelong Learning") that is co-financed by Greece and the E.U. and by the E.C. in the frame of the FP7 project "MeeFS: Multifunctional Energy Efficient Façade System for Building Retrofitting" (EeB.NMP.2011-3, Grant No. 285411). The assistance of Prof. M. Stamatakis and S. Kavouri (Faculty of Geology and Geo-Environment, National and Kapodistrian University of Athens), of Ass. Prof. T. Panidis and Dipl. Ing. V. Papadogianni (Department of Mechanical Engineering and Aeronautics, University of Patras) and of Prof I. Paspaliaris, A. Peppas and N. Athanasakou (School of Mining and Metallurgical Engineering, National Technical University of Athens) in performing the SEM, CC and TGA measurements, respectively, is gratefully acknowledged.

\section{References}

[1] Karlsson, B., and Quintiere, J.G., Enclosure Fire Dynamics, CRC Press, 2000.

[2] Wang, C.Y. and Ang, C.N., "Effect of moisture transfer on specific heat of gypsum plasterboard at high temperatures", Construction and Building Material, 16, 505-515, 2004.

[3] Kontogeorgos, D.A. and Founti, M.A., "Numerical investigation of simultaneous heat and mass transfer mechanisms occurring in a gypsumboard exposed to fire", Applied Thermal Engineering, 30, 1461-1469, 2010.

[4] Kolaitis, D.I. and Founti, M.A., "Development of a solid reaction kinetics gypsum dehydration model appropriate for CFD simulation of gypsum plasterboard wall assemblies exposed to fire", Fire Safety Journal, 58, 151-159, 2013. 
[5] Cabeza, L.F., Castell, A., Barreneche, C., de Gracia, A. and Fernandez, A.I., "Materials used as PCM in thermal energy storage in buildings: A review", Renewable and Sustainable Energy Reviews, 15, 1675-1695, 2011.

[6] Zhou, D., Zhao, C.Y. and Tina, Y., "Review on thermal energy storage with phase change materials (PCMs) in building applications", Applied Energy, 92, 593-605, 2012.

[7] Banu, D., Feldman D., Haghighat, F., Paris, J. and Hawes, D., "Energy-storing wallboard: Flammability tests", Journal of Materials in Civil Engineering, 10, No.2, 98-105, 1998.

[8] Hunger, M., Entrop, A.G., Mandilaras, I., Brouwers, H.J.H. and Founti, M., "The behavior of self-compacting concrete containing micro-encapsulated Phase Change Materials", Cement and Concrete Composites, 3, 731-743, 2009.

[9] Hawlader, M.N.A., Uddin, M.S. and Khin, M.M., "Microencapsulated PCM thermal-energy storage system", Applied Energy, 74, 195-202, 2003.

[10] Sittisart, P. and Farid, M.M, "Fire retardants for phase change materials", Applied Energy, 88, 3140-3145, 2011.

[11] Kosny, J., Yarbrough, D.W., Riazzi, T., Leuthold, D., Smith, J.B. and Bianchi, M., "Development and testing of ignition resistant microencapsulated phase change material", Proceedings of the 11th International Congress on Thermal Energy Storage (Effstock), Stockholm, Sweden 14-17 June, 2009.

[12] Sanchez-Silva, L., Rodriguez, J.F., Romero, A., Borreguero, A.M., Carmona, M., Sanchez, P., "Microencapsulation of PCMs with a styrene-methyl methacrylate copolymer shell by suspension-like polymerisation", Chemical Engineering Journal, 157, 216-222, 2010.

[13] Willax, H., Katz, B., Jung, M.R., Altmann, S., Jahns, E., “Gypsum Wall Board Containing Microencapsulated Latent Heat Accumulator materials”, Patent, appl. Number 20120196116 (2 August 2012).

[14] Schartel, B., and Hull, T.R., "Development of fire-retarded materials - Interpretation of cone calorimeter data", Fire and Materials, 31, 327-354, 2007.

[15] McGraw, J.R. and Mowrer, F.W. , "Flammability and dehydration of painted gypsum wallboard subjected to fire heat fluxes", Fire Safety Science, 6, 1003-1014, 2000.

[16] McGrattan, K., Hostikka, S. and Floyd, J., Fire Dynamics Simulator User's Guide, 2010.

[17] McGrattan, K., Verification and validation of selected fire models for nuclear power plant applications, volume 7: Fire Dynamics Simulator (FDS), Final Report, NUREG-1824, EPRI 1011999, Washington DC, USA, 2006.

[18] Yaws, C.L., Handbook of Thermodynamic and Physical Properties of Chemical Compounds, Knovel, 1996 (update 2004).

[19] Lyon, R.E., "An integral method of non isothermal kinetic analysis", Thermochemical Acta, 297, 117-124, 1997.

[20] Manzello, L.S., Gann, G.R., Kukuck, R.S. and Lenhert, B.D., "Influence of gypsum board type on real fire performance of partition assemblies", Fire and Materials, 31, 425-442, 2007.

[21] EN 1995-1-2, Eurocode 5, Design of timber structures - Part 1-2: General - Structural fire design. 2004. 